\title{
Characterization of Secondary Organic Aerosol Tracers over Tianjin, North China during Summer to Autumn
}

Yu Wang, ${ }^{\dagger}$ Chandra Mouli Pavuluri, ${ }^{*}{ }^{\dagger}$ Pingqing Fu, ${ }^{\dagger}$ Peisen Li, ${ }^{\dagger}$ Zhichao Dong, ${ }^{\dagger}$ Zhanjie Xu ${ }^{\dagger}$ Hong Ren, ${ }^{\dagger}$ Yanbing Fan, ${ }^{\dagger}$ Linjie Li, ${ }^{\ddagger}$ Yan-Lin Zhang, ${ }^{\S}$ and Cong-Qiang Liu ${ }^{\dagger}$

${ }^{\dagger}$ Institute of Surface-Earth System Science, Tianjin University, Tianjin 300072, China

\$LAPC, Institute of Atmospheric Physics, Chinese Academy of Sciences, Beijing 100029, China

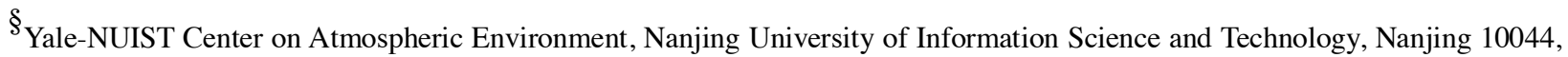
China.

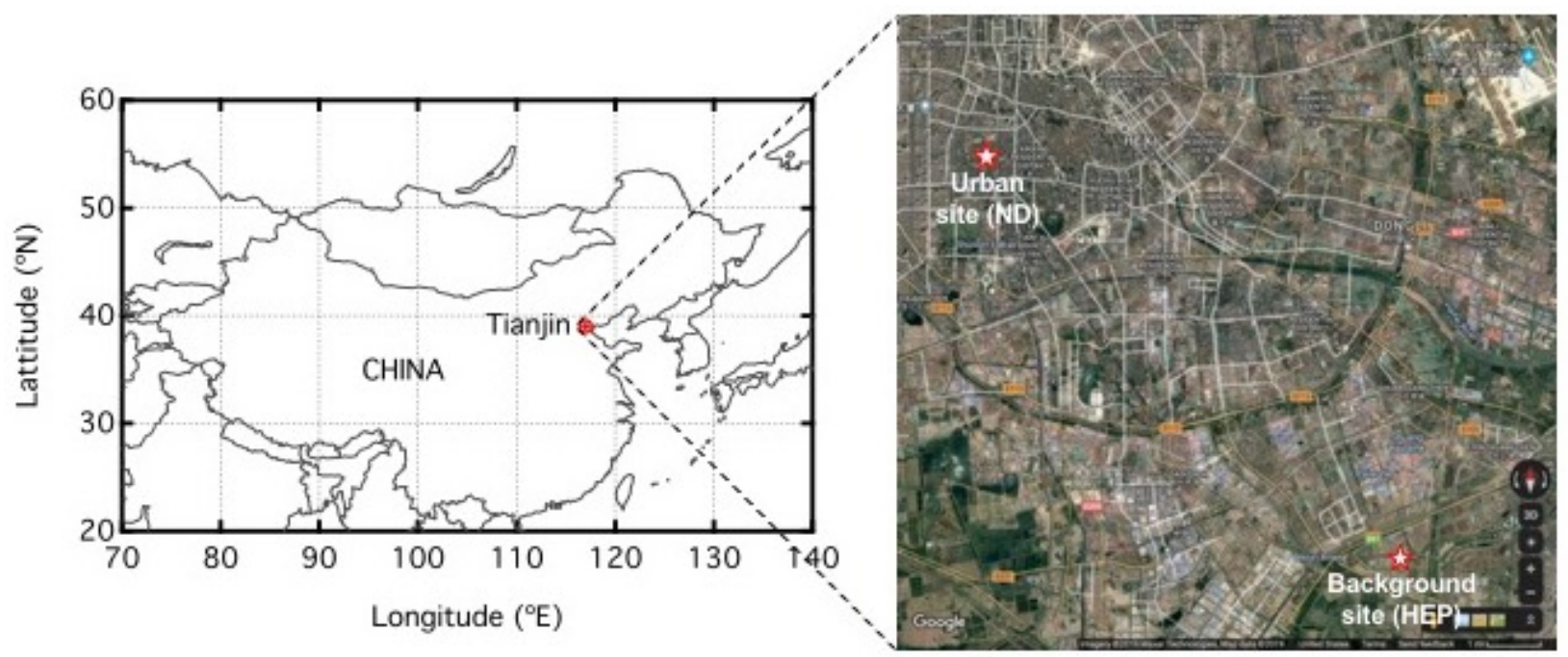

Figure S1. Map of China with an urban site (Nankai District, ND) and a background site (Haihe Education Park, HEP) in Tianjin, North China. 
(a) July

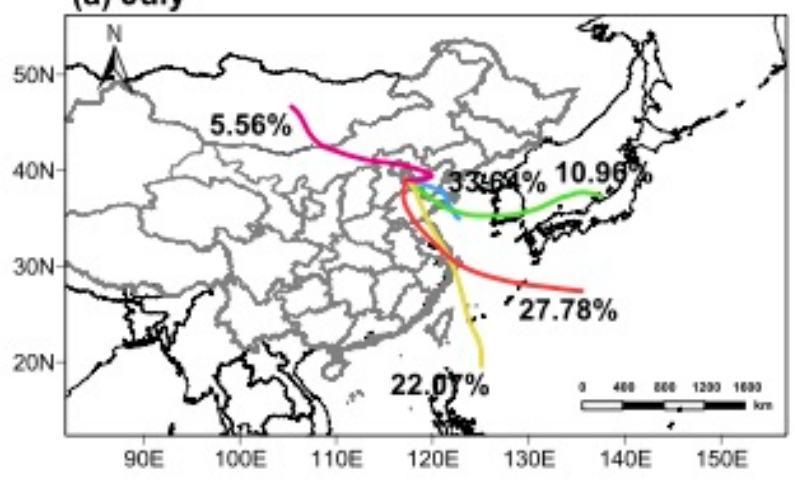

(c) September

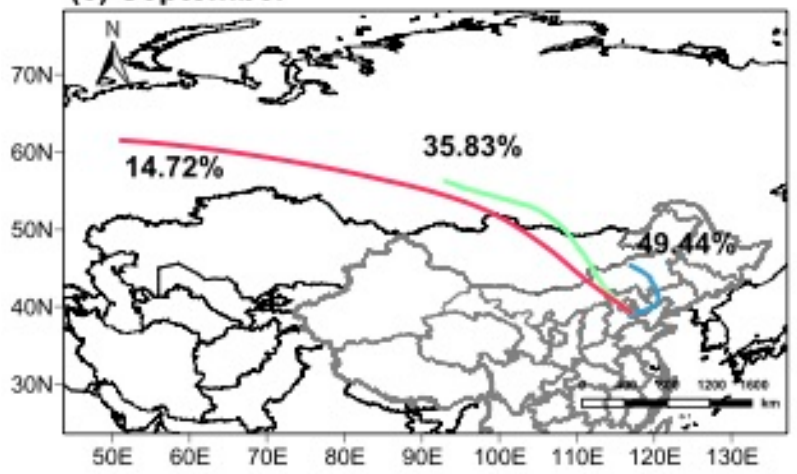

(b) August

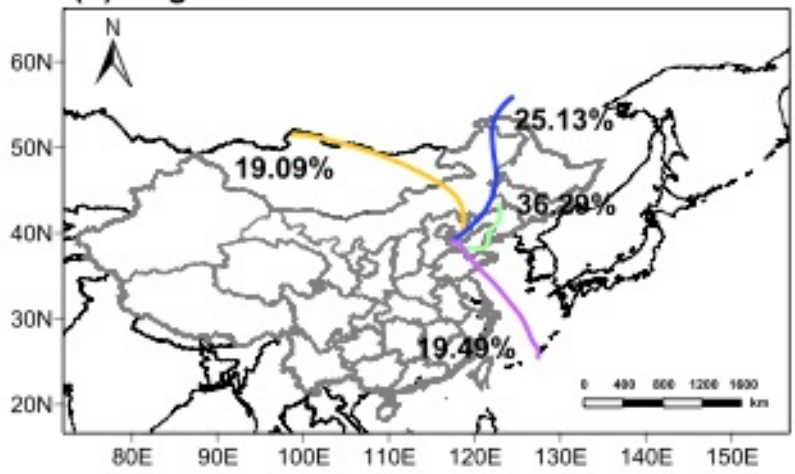

(d) October

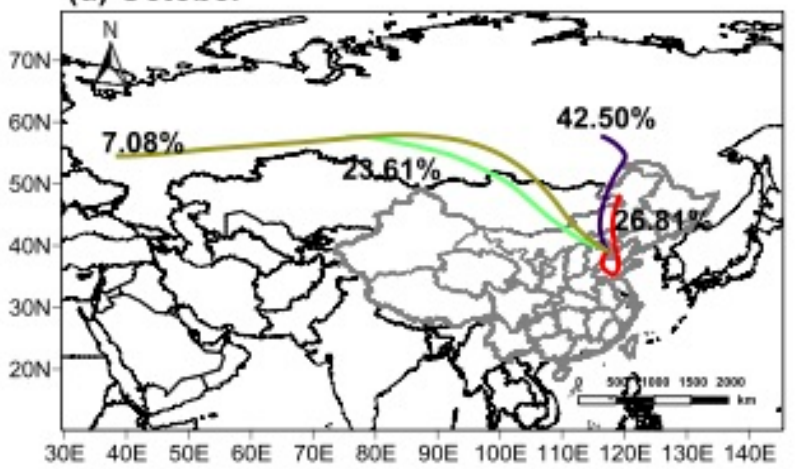

Figure S2. Cluster analysis of the air masses that arrived during (a) July, (b) August, (c) September and (d) October 2018 at $500 \mathrm{~m}$ agl over Tianjin $\left(39.09^{\circ} \mathrm{N}\right.$ and $\left.117.20^{\circ} \mathrm{E}\right)$, North China.

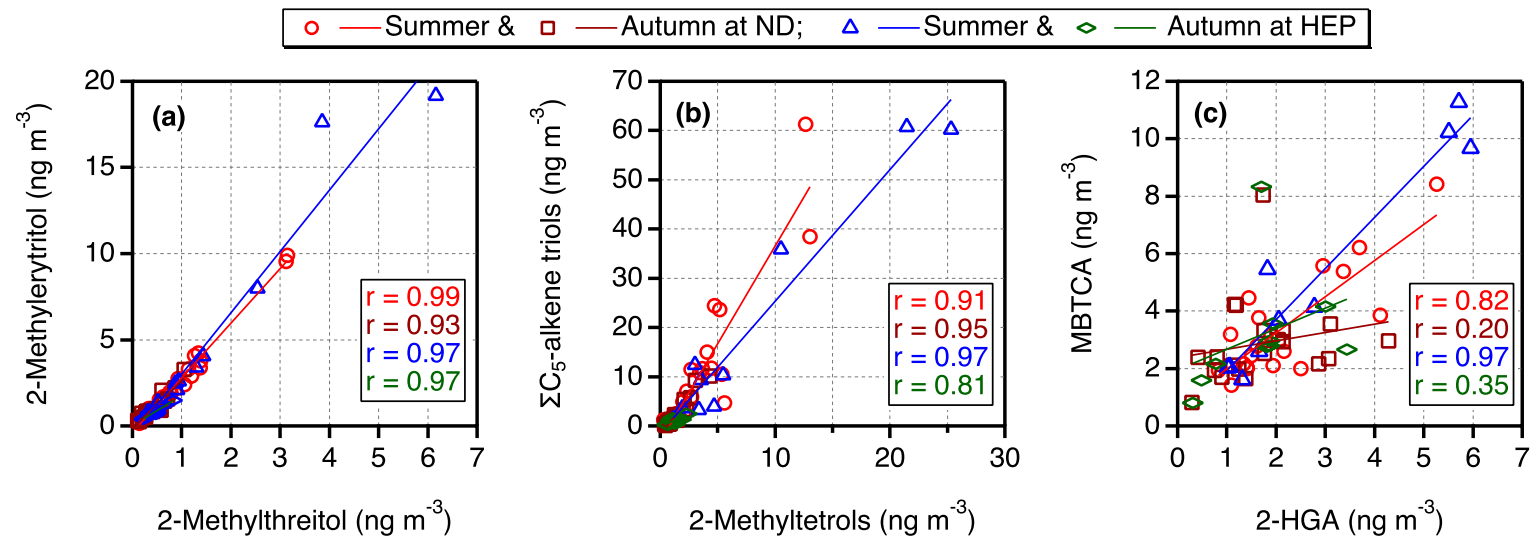

Figure S3. Scatter plots between the selected SOA tracers (a-c) in $\mathrm{PM}_{2.5}$ collected at ND and HEP in Tianjin, North China in summer and autumn (5 July to 30 October) 2018. 


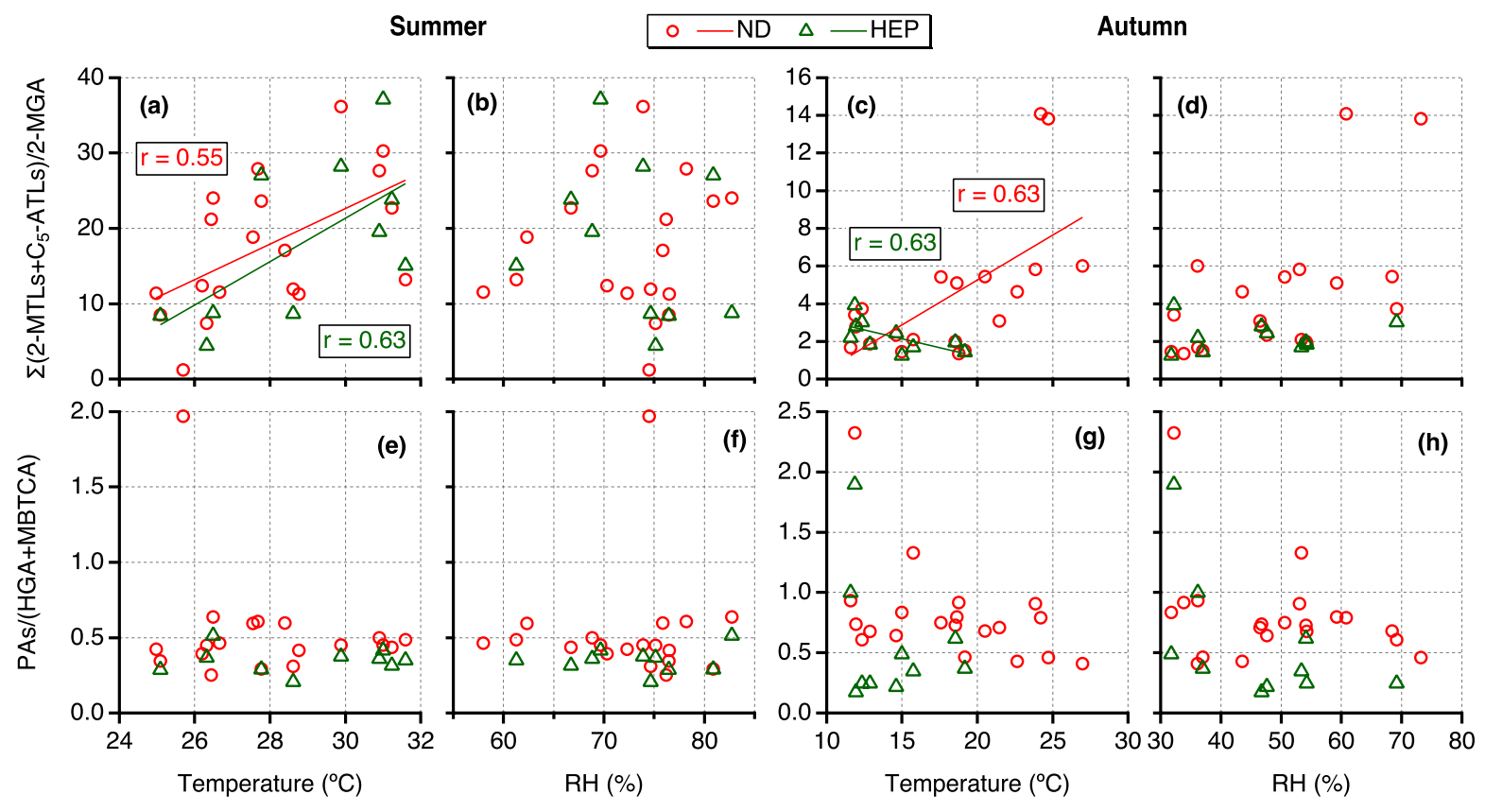

Figure S4. Scatter plots between the mass ratios of selected SOA tracers in $\mathrm{PM}_{2.5}$ at ND and HEP over Tianjin, North China in summer (a, b, e, f) and autumn (c, d, g, h). 


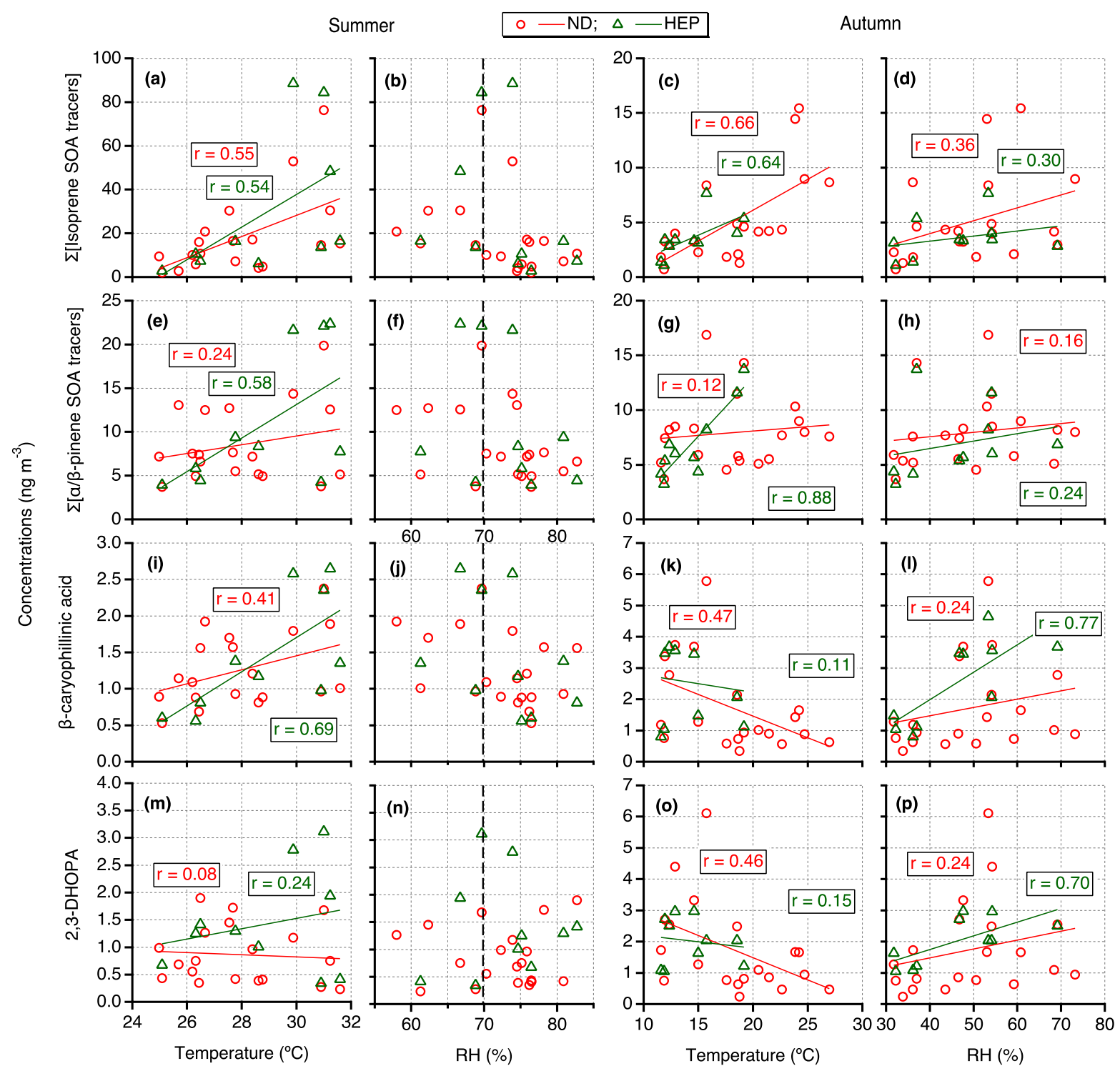

Figure S5. Scatter plots of total isoprene- and (a-d), $\alpha . \beta$-pinene-derived SOA tracers (e-h), $\beta$-caryophyllinic acid (i-1) and 2,3-DHOPA (m-p) with ambient temperature and RH in summer and autumn. 


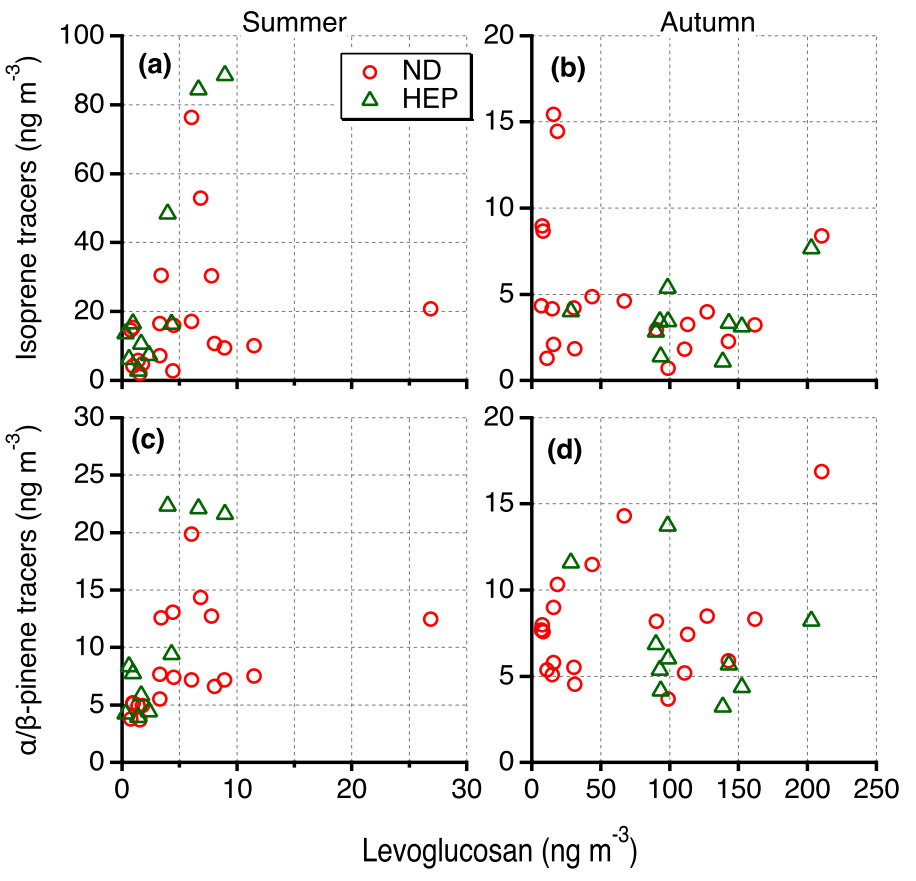

Figure S6. Scatter plots between the selected SOA tracers and levoglucosan, a marker for biomass burning, in $\mathrm{PM}_{2.5}$ at ND and HEP over Tianjin, North China in summer (a, c) and autumn (b, d). 